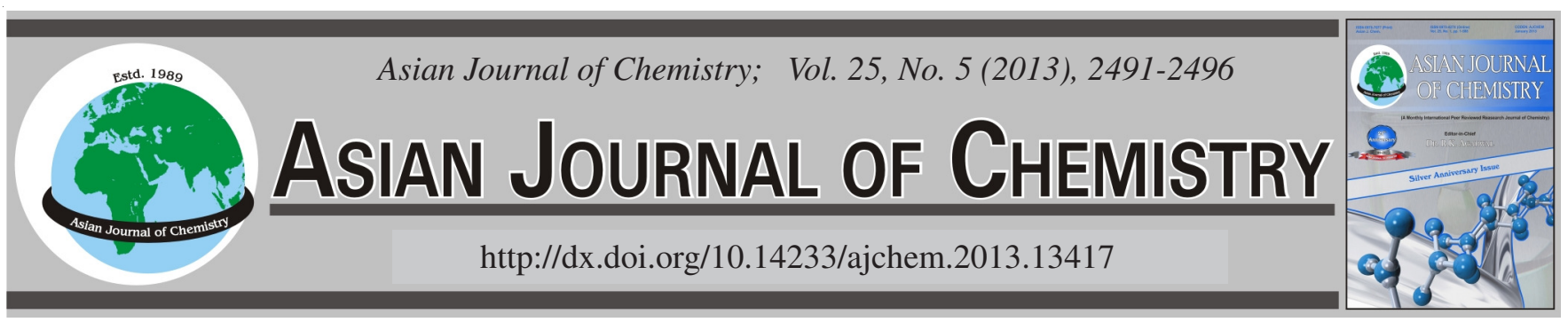

\title{
Removal of Arsenic(III) from Drinking Water by Adsorption with Titanium and Ferrous Oxide Nanoparticles
}

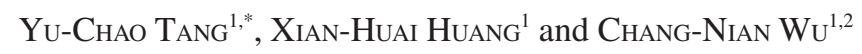

${ }^{1}$ Laboratory of Water Pollution Control and Wastewater Reuse, Department of Environmental Engineering, Anhui University of Architecture, Hefei 230022, P.R. China

${ }^{2}$ School of Chemistry and Materials Science, University of Science and Technology of China, Hefei 230026, P.R. China

*Corresponding author: Fax: +86 551 3828223; Tel: +86 551 3828122; E-mail: tangyc@mail.ustc.edu.cn; tangyc@aiai.edu.cn

\begin{abstract}
Adsorption isotherms and reaction kinetics of arsenic(III) removal from drinking water by adsorption with varying amount of titanium and ferrous oxide [namely $\mathrm{Ti}(\mathrm{OH})_{4}, \mathrm{TiO}_{2}, \mathrm{Fe}_{3} \mathrm{O}_{4}$ and $\mathrm{Fe}_{2} \mathrm{O}_{3}$ ] were evaluated in the present paper. Arsenic(III) can be average removed over $92 \%$ by these titanium or ferrous adsorbents within $2 \mathrm{~h}$ in near neutral solution (include in weak acid and weak alkaline solution). The reaction rate was speedy at initial stage of adsorption but the further time reaction rate was steeply decreased. The removal efficiency of arsenic(III) slightly increased with increasing solution $\mathrm{pH}$ to an adsorption maximum at around $\mathrm{pH} 8$ but steep decreased with further increasing solution $\mathrm{pH}$. Adsorption kinetics data were found to be best described by the modified pseudo-second-order kinetics model for titanium adsorbents $\left[\mathrm{Ti}(\mathrm{OH})_{4}\right.$ and $\left.\mathrm{TiO}_{2}\right]$ but second-order kinetics model for ferrous oxide adsorbents $\left(\mathrm{Fe}_{3} \mathrm{O}_{4}\right.$ and $\left.\mathrm{Fe}_{2} \mathrm{O}_{3}\right)$. Langmuir and Freundlich isotherms all fit the data but not very well. Maximum adsorption capacity $(\mathrm{mg} / \mathrm{g})$ calculated from the slope and the intercept of the graph of Dubinin-Radushkevich (D-R) isotherm were found to be $19.22 \mathrm{mg} / \mathrm{g}$ of Ti(OH) $4,4.64 \mathrm{mg} / \mathrm{g}$ of TiO ${ }_{2}$ and $66.42 \mathrm{mg} / \mathrm{g}$ of $\mathrm{Fe}_{3} \mathrm{O}_{4}$, respectively. Results of adsorption isotherms and reaction kinetics suggested the adsorption of arsenic(III) on titanium and ferrous oxide nano-particles were controlled by chemical process at low concentration but physical in high range.
\end{abstract}

Key Words: Arsenic(III), Drinking water, Adsorbent, Adsorption isotherms, Reaction kinetics.

\section{INTRODUCTION}

Widespread contamination of drinking water with arsenic has been a serious problem, especially in West Bengal, India, Bangladesh, Chile, Vietnam and China. The presence of arsenic in drinking water is mostly due to natural geological processes such as weathering reactions, biological activity and volcanic emissions, as well as anthropogenic activities ${ }^{1}$. Since arsenic is highly toxic and carcinogenic, the WHO, U.S. EPA and a number of countries has revised the guideline for arsenic maximum contaminant level in drinking water from 50 to 10 $\mu \mathrm{g} / \mathrm{L}$. Even, the state of New Jersey of USA proposed that the total arsenic in drinking water should be less than $5 \mu \mathrm{g} / \mathrm{L}$ to ensure the health of people ${ }^{2}$.

A number of treatment techniques have been developed for the removal of arsenic from drinking water, namely, coagulation, ion-exchange, adsorption and reverse osmosis. Among various arsenic removal technologies, coagulation and adsorption are believed to be a relative simple, efficiency and cost effective processes ${ }^{3-5}$. Many coagulation and adsorption technologies have been reported to be capable of removing arsenic to levels lower than $50 \mu \mathrm{g} / \mathrm{L}$, but with the implementation of revision the permissible levels to $10 \mu \mathrm{g} / \mathrm{L}$ or lower, it is necessary to investigate new treatment approaches or materials that would provide drinking water with arsenic satisfy the maximum contaminant level.

Due to its non-ionic existence as As(III) in natural water, it is generally reported to have low affinity to the surface of various adsorbents or coagulants compared with $\mathrm{As}(\mathrm{V})^{6}$. Therefore $\mathrm{As}(\mathrm{III})$ is less efficiently removed than $\mathrm{As}(\mathrm{V})$ from aqueous solutions by almost all coagulation and adsorption techniques and preoxidation of As(III) to As(V) using some oxidizing chemical agents like chlorine and potassium permanganate is necessary for better removal ${ }^{7}$. However, most arsenic-enriched groundwater is generally dominated by As(III), up to $96 \%$ of total arsenic. Further more, As(III) is more mobile in groundwater and 25-60 times more toxic than $\mathrm{As}(\mathrm{V})^{8}$.

Nanoparticle $\mathrm{TiO}_{2}$ and ferrous oxide (include $\mathrm{Fe}_{2} \mathrm{O}_{3}$ and $\mathrm{Fe}_{3} \mathrm{O}_{4}$ ) attracted a lot of research interest as promising arsenic especially arsenite(III) adsorbents because of their high stability, non-toxicity and demonstrated high arsenic removal capability. In the present work, arsenite(III) removal from drinking water by adsorption with several adsorbents of 
titanium or ferrous oxide were studied. Adsorption isotherms and kinetics of the adsorption reaction of the As(III) on the these adsorbents were discussed.

\section{EXPERIMENTAL}

The titanium and ferrous oxide adsorbents were prepared by a hydrolysis process. A liquid tetrabutyl titanate $\left[\mathrm{Ti}\left(\mathrm{OC}_{4} \mathrm{H}_{9}\right)_{4}\right.$, $99.0 \%$ ], $\mathrm{FeCl}_{2}$ and $\mathrm{FeCl}_{3}$ were used in the hydrolysis process as the raw material. Arsenic(III) oxide $\left(\mathrm{As}_{2} \mathrm{O}_{3}\right.$, Jingchun Chemical Reagent Co. Ltd., Shanghai) was used to prepare As(III) stock solution and concentrated hydrochloride acid $(\mathrm{HCl}, 32-38 \%)$ and sodium hydroxide $(\mathrm{NaOH}, 99 \%)$ were used to stabilize the arsenic species or as precipitant. All the chemicals and materials used were of analytical grade without further purification and purchased from Sinopharm Chemical Reagent Co. Ltd., Shanghai except the $\mathrm{As}_{2} \mathrm{O}_{3}$.

Adsorbent preparation: An aqueous $\mathrm{Ti}\left(\mathrm{OC}_{4} \mathrm{H}_{9}\right)_{4}$ of 50 $\mathrm{mL}$ was hydrolyzed by drop-wise addition of aqueous $\mathrm{NaOH}$ as the precipitator with a rate of $1 \mathrm{~mL} / \mathrm{min}$ until the $\mathrm{pH}$ of the mixture reached 9 . The hydrolysis was performed at $20^{\circ} \mathrm{C}$. The obtained hydrolysis product was white, then rinsed with de-ionized water for $1 \mathrm{~h}$ to remove remained organism. After dried at $85^{\circ} \mathrm{C}$ for $12 \mathrm{~h}$, the powder was white and denoted as $\mathrm{Ti}(\mathrm{OH})_{4}$. Then the white powder was calcined in ambient atmosphere at $400{ }^{\circ} \mathrm{C}$ for $2 \mathrm{~h}$ and denoted as $\mathrm{TiO}_{2}$.

The preparing procedures of ferrous oxide adsorbents were detailed as follows: Firstly, the mixed solution of $\mathrm{FeCl}_{2} \cdot 4 \mathrm{H}_{2} \mathrm{O}(0.100 \mathrm{~mol} / \mathrm{L})$ and $\mathrm{FeCl}_{3} \cdot 6 \mathrm{H}_{2} \mathrm{O}(0.100 \mathrm{~mol} / \mathrm{L})$ was prepared by dissolving $1.988 \mathrm{~g} \mathrm{FeCl}_{2} \cdot 4 \mathrm{H}_{2} \mathrm{O}$ and $2.703 \mathrm{~g}$ $\mathrm{FeCl}_{3} \cdot 6 \mathrm{H}_{2} \mathrm{O}$ together in $100 \mathrm{~mL}$ deionized water. The $\mathrm{NaOH}$ solution $(0.200 \mathrm{~mol} / \mathrm{L})$ was prepared by dissolving $0.80 \mathrm{~g}$ $\mathrm{NaOH}$ in $100 \mathrm{~mL}$ deionized water. Then, the two solutions were mixed sufficiently with equal volumes. The precipitate was dried at $85^{\circ} \mathrm{C}$ for $12 \mathrm{~h}$, the powder was black and denoted as $\mathrm{Fe}_{3} \mathrm{O}_{4}$. Then the black powder was calcined in ambient atmosphere at $400{ }^{\circ} \mathrm{C}$ for $2 \mathrm{~h}$. Then the colour of the powder was changed from black to red and denoted it as $\mathrm{Fe}_{2} \mathrm{O}_{3}$. All the obtained adsorbent was ground to fine powder in an agate mortar for use.

Arsenic sorption experiments: The adsorption experiments for As(III) removal by varying amount of adsorbents were determined in batch reactors. By adding 0.015, 0.025, 0.05, $0.10,0.20$ and $0.50 \mathrm{~g}$ of adsorbents into $100 \mathrm{~mL}$ glass bottles contaminated $1.00 \mathrm{mg} / \mathrm{L} \mathrm{As}(\mathrm{III})$. Suspension settle in sealed homoeothermic incubator, shake velocity at $60 \mathrm{rpm}$.

Experiments to determine adsorption rates and kinetics were carried out by adding $0.200 \mathrm{~g}$ of adsorbents into 1000 $\mathrm{mL}$ glass bottles contaminated $1.00 \mathrm{mg} / \mathrm{L} \mathrm{As}(\mathrm{III})$. Before adding the adsorbent, As(III) solution was heated to designated temperature. Suspension settle in sealed homoeothermic incubator, shake velocity at $60 \mathrm{rpm}$.

Adsorption isotherms were obtained by adding different amounts of absorbent into $100 \mathrm{~mL}$ As(III) solutions initial concentration at $1.00 \mathrm{mg} / \mathrm{L}$. The temperature was control at $25^{\circ} \mathrm{C}$. After $24 \mathrm{~h}$ of mixing, suspension samples were withdrawn and filtered through $0.45 \mu \mathrm{m}$ filter film.

The $\mathrm{pH}$ of the solutions was adjusted with $\mathrm{HCl}$ and $\mathrm{NaOH}$ to designated values (about $\mathrm{pH}=7$ ) by using a potential meter
(FE20, Mettler Toledo Instrument Co. Ltd.) in above experiments. After an aliquot was sampled, filter the sample immediately through $0.45 \mu \mathrm{m}$ filter film (Millipore Corporation, USA). Variations in the concentration of As(III) of each particleremoved sampled solution were monitored using atomic absorption spectrophotometer (TAS-990, Beijing Puxi Instrument Co. Ltd.) with an As hole cathode lamp. A hydride generation system was connected to the equipment and the arsine was atomized in a quartz cell.

\section{RESULTS AND DISCUSSION}

Effect of absorbent dosage: The removal efficiency of arsenic by adsorption reaction of As(III) solution was investigated with different initial concentrations of varying amount of adsorbents $(0.15-5 \mathrm{~g} / \mathrm{L})$. Fig. 1 shows that the concentration of As(III) decreased with higher concentrations of varying amount of adsorbents. As(III) can be removed over $85 \%$ when dosage of $\mathrm{Fe}_{2} \mathrm{O}_{3}$ or $\mathrm{Ti}(\mathrm{OH})_{4}$ was $1 \mathrm{~g} / \mathrm{L}$. Removal efficiency can only slightly increased with increasing adsorbent dosage when dosage over $1 \mathrm{~g} / \mathrm{L}$, for example, removal efficiency increased from $33.4 \%$ to $85.6 \%$ with the dosage of $\mathrm{Ti}(\mathrm{OH})_{4}$ increasing from $0.2 \mathrm{~g} / \mathrm{L}$ to $1.0 \mathrm{~g} / \mathrm{L}$, but from $85.6 \%$ to $96.9 \%$ with the dosage increasing from $1.0 \mathrm{~g} / \mathrm{L}$ to $5.0 \mathrm{~g} / \mathrm{L}$. The As(III) can be removed over $92 \%$ by these titanium or ferrous adsorbents within $2 \mathrm{~h}$ suggested As(III) can be treated well by adsorption process. Lackovic et al. ${ }^{9}$ used zero-valent iron as an adsorption medium and observed more than $95 \%$ of arsenic removal efficiency in both the laboratory and field column studies. But few literatures had reported As(III) in higharsenic contaminated groundwater can be treated to satisfy the maximum contaminant level just by adsorption technique alone if without other assistant process such as pre-process or co-process ${ }^{3,10}$. The residual As(III) in the solution far exceed the arsenic standard ( $10 \mu \mathrm{g} / \mathrm{L}$ in drinking water) even the dosage over $5 \mathrm{~g} / \mathrm{L}$ may suggest there should be co-technique using when these adsorbents application in drinking water purification if the initial concentration of As(III) is very high.

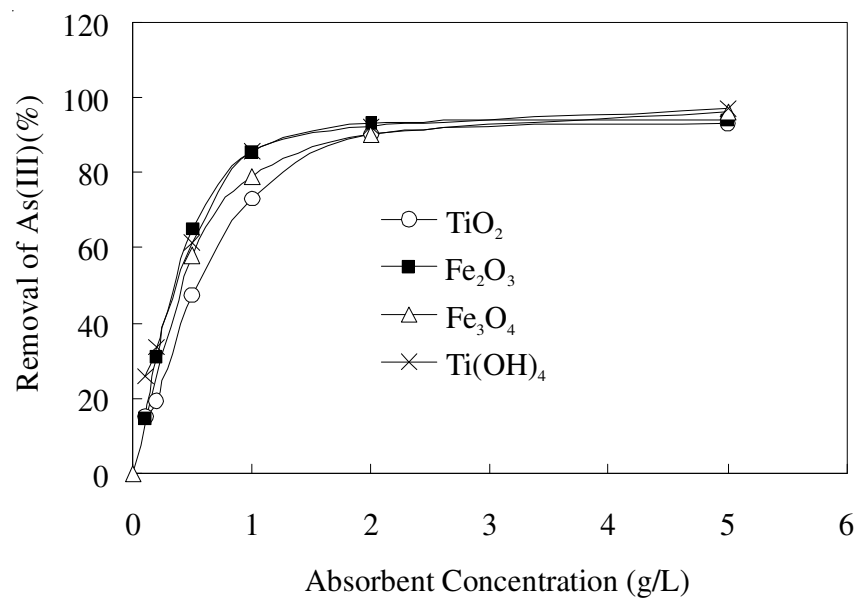

Fig. 1. Effect of adsorbent concentration on As(III) adsorption from solution by varying amount of adsorbents, with reaction conditions: contact time $=2 \mathrm{~h}$, initial As concentration $=1.00 \mathrm{mg} / \mathrm{L}$

Effect of pH: Effect of $\mathrm{pH}$ on As(III) adsorption by varying amount of adsorbents were shown in Fig. 2. The removal 
efficiency of As(III) in near neutral solution (include in weak acid and weak alkaline solution) may indicate existence in non-ionic $\mathrm{H}_{3} \mathrm{AsO}_{3}$ in neutrally water doesn't suppress contact of As(III) with the experimented adsorbents. This result may indicate strong binding force between the non-ionic $\mathrm{H}_{3} \mathrm{AsO}_{3}$ and the adsorbents could be achieved in the adsorption process. But the removal of As(III) decreasing obviously when $\mathrm{pH}$ of solution decreased from 6 to 3 . The As(III) species in form of $\mathrm{H}_{3} \mathrm{AsO}_{3}$ almost $100 \%$ with $\mathrm{pH}$ value less than 7 . The decreased effect with decreasing $\mathrm{pH}$ may caused by surface properties changed in the acid conditions.

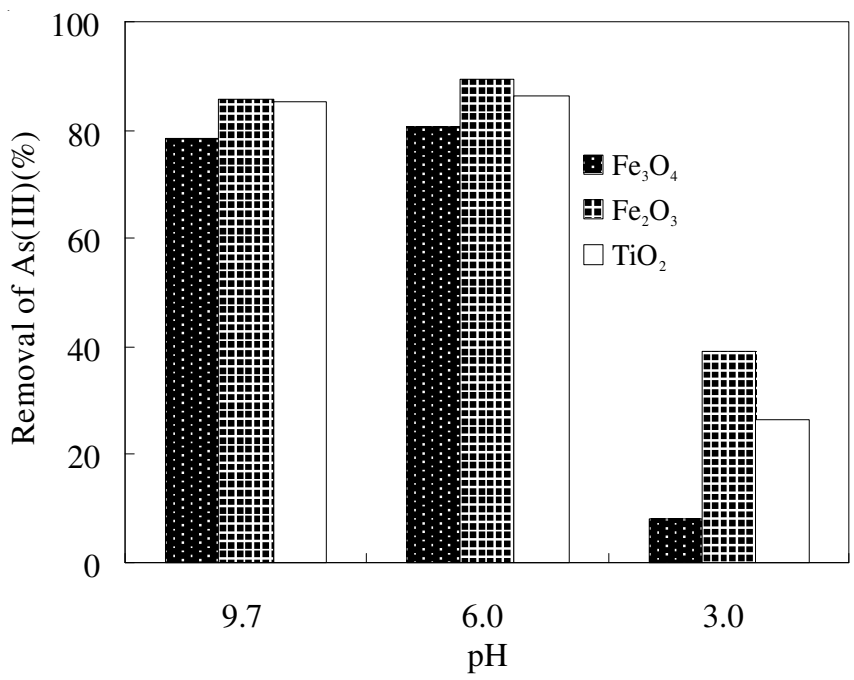

Fig. 2. Effect of $\mathrm{pH}$ on $\mathrm{As}(\mathrm{III})$ adsorption from solution by varying amount of adsorbents, with reaction conditions: contact time $=2 \mathrm{~h}$, initial As concentration $=1.00 \mathrm{mg} / \mathrm{L}$, adsorbent dosage $=2.0 \mathrm{~g} / \mathrm{L}$

In order to evaluate effects of $\mathrm{pH}$ on $\mathrm{As}(\mathrm{III})$ adsorption, further experiments conduct on titanium dioxide under different $\mathrm{pHs}$ were performed. The results were shown in Fig. 3. The experimental observations showed that modified pseudosecond-order kinetics constants of As(III) removal slightly increases with increasing solution $\mathrm{pH}$ to an adsorption maximum around $\mathrm{pH} 8$ and steep decreases with further increases in solution $\mathrm{pH}$. Similar As(V) adsorption behaviours were observed before ${ }^{11,12}$.

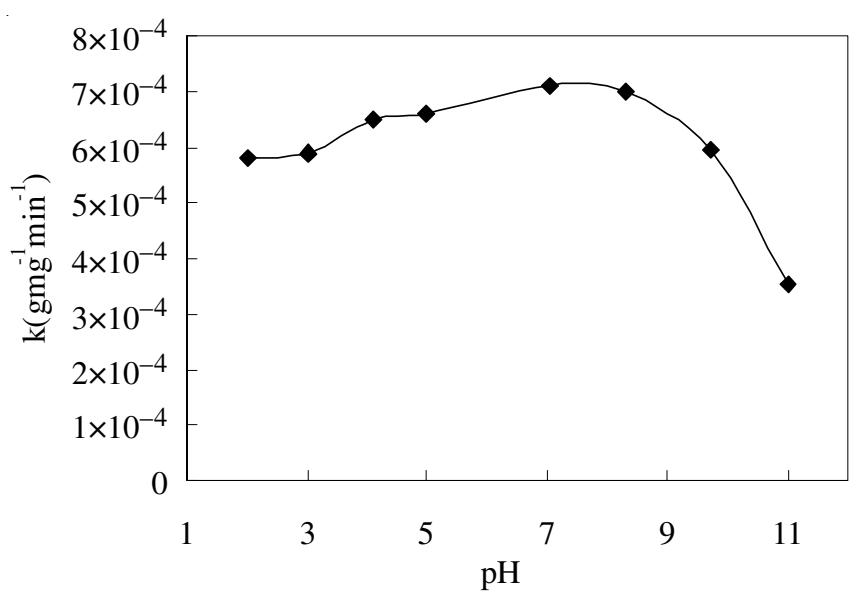

Fig. 3. Effect of $\mathrm{pH}$ on $\mathrm{As}(\mathrm{III})$ adsorption from solution by $\mathrm{TiO}_{2}$ adsorbent, with reaction conditions: contact time $=2 \mathrm{~h}$, initial As concentration $=0.150 \mathrm{mg} / \mathrm{L}$, adsorbent dosage $=0.2 \mathrm{~g} / \mathrm{L}$
The $\mathrm{p} K \mathrm{a}_{1}, \mathrm{p} K \mathrm{a}_{2}$ and $\mathrm{p} K \mathrm{a}_{3}$ values of $\mathrm{H}_{3} \mathrm{AsO}_{3}$ are 9.22, 12.3 and 13.4 , respectively, so, $\mathrm{As}(\mathrm{III})$ predominately exists as $\mathrm{H}_{3} \mathrm{AsO}_{3}$ when $\mathrm{pH}$ is in the range of $2-7^{13}$. Relatively higher adsorption of $\mathrm{As}(\mathrm{III})$ in the $\mathrm{pH}$ range 2-7 can be attributed to surface complexes formed but not the electrostatic attraction between the $\mathrm{H}_{3} \mathrm{AsO}_{3}$ and positively charged surface of $\mathrm{TiO}_{2}$ $\left(\mathrm{H}^{+}+\mathrm{Ti}-\mathrm{OH} \rightarrow \mathrm{Ti}^{-} \mathrm{OH}_{2}{ }^{+}, \mathrm{pKs}=4.58\right)$. Whereas the decrease in adsorption when $\mathrm{pH}>7$ can be attributed to electrostatic repulsion between $\mathrm{AsO}(\mathrm{OH})_{2}{ }^{-}$and the negatively charged surface of $\mathrm{TiO}_{2}\left(\mathrm{OH}^{-}+\mathrm{Ti}-\mathrm{OH} \rightarrow \mathrm{Ti}-\mathrm{OOH}_{2}^{-}\right)$. Pena and Jing et al. ${ }^{14}$ had reported the surface complexes formed between $\mathrm{TiO}_{2}$ and arsenic species and maintained the non-protonated speciation at $\mathrm{pH}$ values from 5 to 10 and the dominant surface species were $(\mathrm{TiO})_{2} \mathrm{AsO}_{2}^{-}$and $(\mathrm{TiO})_{2} \mathrm{AsO}^{-}$for $\mathrm{As}(\mathrm{V})$ and As(III), respectively. Otherwise, the $\mathrm{pH}$ increase led to the dramatic decrease of As(III) removal rate in alkaline solution $(\mathrm{pH}>9)$ was also attributed to decrease of numbers of positively charged active sites on particle surfaces and to the increase in numbers of $\mathrm{OH}^{-}$ions competitive with arsenic for adsorption on titanium dioxide surface.

Reaction kinetics: The effect of contact time (10-120 min) on arsenic adsorption in As(III) batches reactor is shown in Fig. 4. The results clearly demonstrate that adsorption efficiencies increased rapidly with an increase in contact time up to $20 \mathrm{~min}$ and maximum removal of $91.8,93.6$ and $96.5 \%$ were achieved with a contact time of 120 min by $\mathrm{Fe}_{3} \mathrm{O}_{4}, \mathrm{Fe}_{2} \mathrm{O}_{3}$ and $\mathrm{TiO}_{2}$, respectively. Most of $\mathrm{As}(\mathrm{III})$ in the solution can adsorb onto the adsorbents in a short time, about $80 \%$ of As(III) be removed less than $40 \mathrm{~min}$. The reaction rate was very speedy at initial stage of adsorption but was steeply decreased in the further time. Xu et al. ${ }^{8}$ had reported most of the As(III) in the solution was adsorbed onto $\mathrm{TiO}_{2} \cdot \mathrm{xH}_{2} \mathrm{O}$ nano-particles in a short time, e.g., around $52 \% \mathrm{As}(\mathrm{III})$ in the solution was adsorbed in just 15 min when the $\mathrm{TiO}_{2} \cdot \mathrm{xH}_{2} \mathrm{O}$ loading concentration was just $0.04 \mathrm{~g} / \mathrm{L}$ (40 ppm). Guo et al. ${ }^{6}$ reported equilibrium adsorption time need more than $190 \mathrm{~h}$ when they using natural siderite as the adsorbent to remove arsenic(III) and $\operatorname{arsenic}(\mathrm{V})$ from groundwater. This may indicate rapid reaction rate in the initial stage of reaction can be archived in the adsorption process treated by these titanium or ferrous compound adsorbents.

The As(III) adsorption kinetics data were found to be best described by the modified pseudo-second-order kinetics model(Fig. 5a and b) for titanium adsorbent $\left[\mathrm{Ti}(\mathrm{OH})_{4}\right.$ and $\mathrm{TiO}_{2}$ ], which can be described by eqn. 1 .

$$
\frac{1}{Q_{e}-Q_{t}}-\frac{1}{Q_{e}}=k \cdot t^{n}
$$

where, $Q_{t}$ is amount of $\mathrm{As}(\mathrm{III})$ adsorbed at time $t$, where $\mathrm{Q}_{\mathrm{e}}$ is amount of $\mathrm{As}$ (III) adsorbed at equilibrium time and $\mathrm{k}$ and $\mathrm{n}$ are rate constant and order respectively ${ }^{8,15}$. In a general pseudosecond-order kinetics model, $\mathrm{n}$ in the equation was 1 . A number of power-function kinetic models which expressed by eqn. 2 were reported in heterogeneous systems ${ }^{13,16}$.

$$
\mathrm{Q}_{\mathrm{t}}=\mathrm{k} \cdot \mathrm{t}^{\mathrm{n}}
$$

At the initial stage of adsorption, adsorption rate approximately direct proportionality to concentration of dissolved As(III) in solution, thus, first-order reaction model or pseudo- 


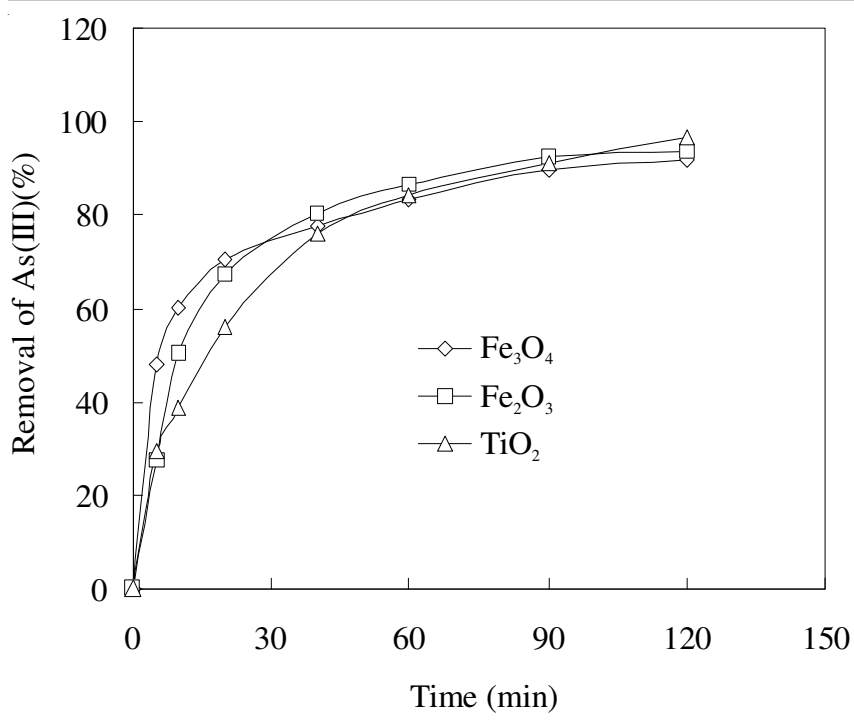

Fig. 4. Effect of contact time on As(III) adsorption from solution by varying amount of adsorbents, with reaction conditions: initial As concentration $=1.00 \mathrm{mg} / \mathrm{L}$, adsorbent dosage $=2.00 \mathrm{~g} / \mathrm{L}$

first-order reaction model may described adsorption kinetics data. When adsorption process almost reached equilibrium state, apparent adsorption rate decreased to 0 whatever the concentration of residual As(III). Thus, kinetic model may appear in reaction rate with a function of time, this was often occurred in a heterogeneous system especially reaction control by diffusion within pores. Data were tested by least-square regression analysis and correlation coefficient $\left(\mathrm{R}^{2}\right)$ of modified pseudo-second model were 0.9917 and 0.9882 at $298 \mathrm{~K}, 0.9793$ and 0.9892 at $323 \mathrm{~K}$ for $\mathrm{Ti}(\mathrm{OH})_{4}$ and $\mathrm{TiO}_{2}$, respectively. The closeness of $\mathrm{R}^{2}$ to 1 indicates that the model fitted the experimental data accurately. In each case, the high coefficient of determination value $\left(\mathrm{R}^{2}>0.98\right)$ suggests that the uptake of arsenic (III) varies almost linearly with $\mathrm{t}^{0.5}$, which reflects the characteristics of intraparticle diffusion ${ }^{17,18}$. This suggests that the adsorption of As(III) on these titanium adsorbents was governed by the diffusion within pores of the adsorbent. Badruzzaman et al. ${ }^{19}$ observed similar results during the adsorption of arsenic (V) onto granular ferric hydroxide.

The adsorption kinetics data were found to be best described by the second-order kinetics model (Fig. 5c) for ferrous oxide adsorbent $\left(\mathrm{Fe}_{3} \mathrm{O}_{4}\right.$ and $\left.\mathrm{Fe}_{2} \mathrm{O}_{3}\right)$, which can be described by the eqn. 3.

$$
\frac{1}{\mathrm{C}_{\mathrm{t}}}-\frac{1}{\mathrm{C}_{0}}=\mathrm{kt}
$$

where, $\mathrm{C}_{\mathrm{t}}$ is concentration of $\mathrm{As}(\mathrm{III})$ in solution at time $\mathrm{t}, \mathrm{C}_{0}$ is initial a concentration of $\mathrm{As}(\mathrm{III})$ in solution ${ }^{20}$. A plot of $\left(1 / C_{t}-1 / C_{0}\right)$ versus $t$ for the adsorption under consideration is shown in Fig. 5. The correlation coefficient $\left(\mathrm{R}^{2}\right)$ were 0.9299 for $\mathrm{Fe}_{2} \mathrm{O}_{3}, 0.9902$ for $\mathrm{Fe}_{3} \mathrm{O}_{4}$ indicates that the adsorption followed the second-order reaction model well. The reaction rates were speedy at initial stage of adsorption but the further time reaction was steeply decreased. This indicates the adsorption reaction may divide into two separated process. The initial adsorption was controlled by chemical adsorb which occurred between $\mathrm{H}_{3} \mathrm{AsO}_{3}$ and these titanium and ferrous oxide nano-particles. After monolayer surface of the adsorbent was sufficient with the chemical adsorbed $\mathrm{H}_{3} \mathrm{AsO}_{3}$. further adsorption on multiple-layer coverage of homogeneous surface may happen through physical process by van der Waals force.
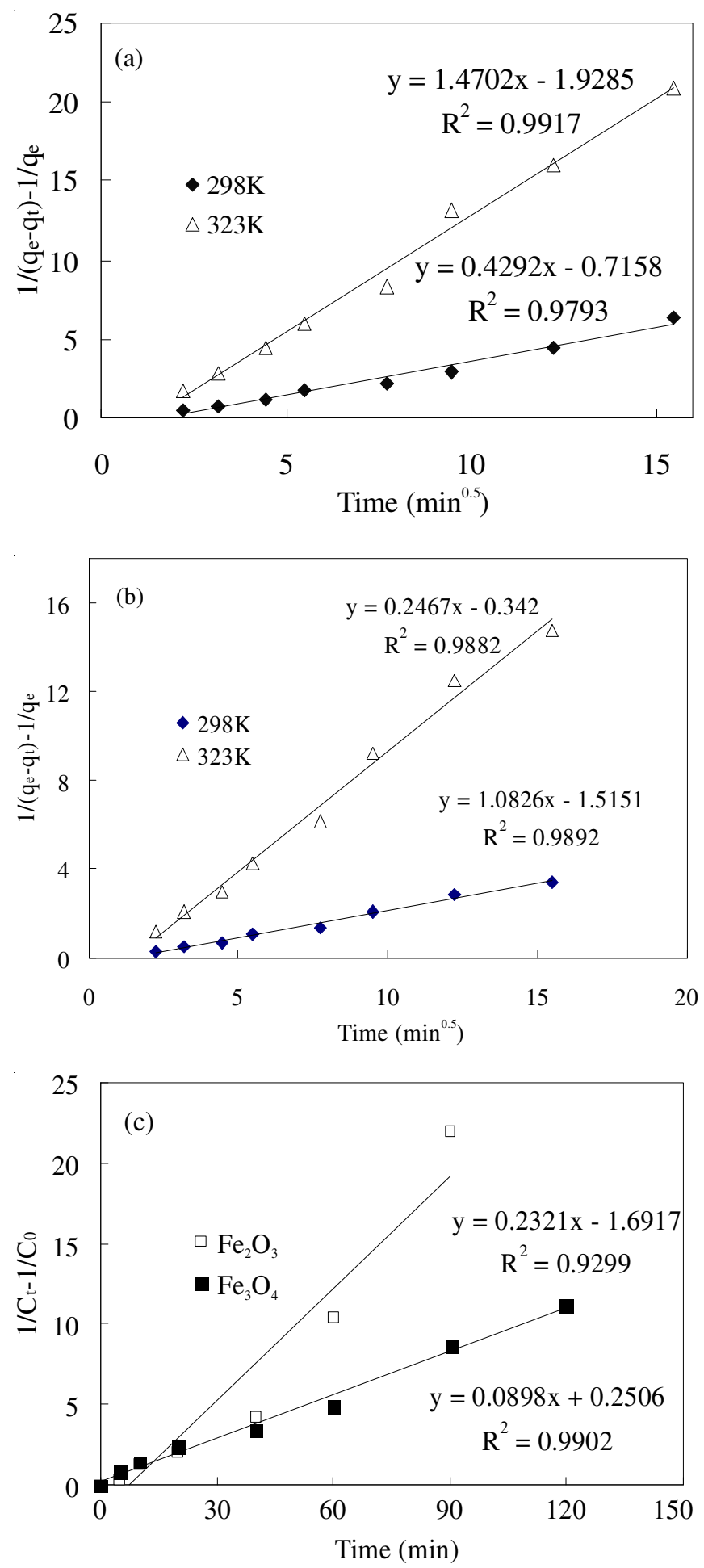

Fig. 5. Second-order (c) and modified pseudo-second-order (a, b) kinetics model of the reaction of As(III) adsorption from solution by varying amount of adsorbents, with reaction conditions: initial As concentration $=1.00 \mathrm{mg} / \mathrm{L}$, adsorbent dosage $=2.00 \mathrm{~g} / \mathrm{L}$. (a) $\mathrm{Ti}(\mathrm{OH})_{4}$, (b) $\mathrm{TiO}_{2}$, (c) $\mathrm{Fe}_{2} \mathrm{O}_{3}, \mathrm{Fe}_{3} \mathrm{O}_{4}$

Adsorption isotherms: Langmuir isotherm model assumes a monolayer surface coverage limiting the adsorption due to the surface saturation, while the Freundlich isotherm 
model is an empirical model allowing for multilayer adsorption $^{6}$. Langmuir adsorption isotherm equation can be expressed by the eqn. 4 .

$$
\frac{1}{Q_{e}}=\frac{1}{Q_{m}}+\frac{1}{Q_{m} b} \cdot \frac{1}{C_{e}}
$$

where, $\mathrm{Q}_{\mathrm{e}}$ is the specific adsorbed quantity of a model pollutant compound and $\mathrm{C}_{\mathrm{e}}$ is the concentration of which, both at equilibrium; $\mathrm{Q}_{\mathrm{m}}$ is the saturation (maximum) adsorption capacity and $b$ is the ratio of $\mathrm{K}_{\mathrm{a}} / \mathrm{K}_{\mathrm{d}}, \mathrm{K}_{\mathrm{a}}$ is the adsorption constant and $\mathrm{K}_{\mathrm{d}}$ is the de-sorption constant. Freundlich adsorption isotherm equation can be expressed by the eqn. 5 .

$$
\ln \mathrm{Q}_{\mathrm{e}}=\ln \mathrm{k}_{\mathrm{f}}+\frac{1}{\mathrm{n}} \ln \mathrm{C}_{\mathrm{e}}
$$

where, $\mathrm{K}_{\mathrm{f}}$ and $\mathrm{n}$ are two Freundlich isotherm parameters.

Equilibrium adsorption of As(III) by varying amount of adsorbents was shown in Fig. 6 and Langmuir isotherm model in Fig. 7 while Freundlich isotherm model was shown in Fig. 8. The respective empirical constants for the Langmuir and Freundlich isotherm models along with correlated coefficients $\left(\mathrm{R}^{2}\right)$ were presented in Table- 1 . The $\mathrm{R}^{2}$ values obtained from the Langmuir isotherm were $0.932,0.984$ and 0.928 of $\mathrm{Ti}(\mathrm{OH})_{4}, \mathrm{TiO}_{2}$ and $\mathrm{Fe}_{3} \mathrm{O}_{4}$, respectively. The $\mathrm{R}^{2}$ values obtained from the Freundlich isotherm were $0.934,0.943$ and 0.963 of $\mathrm{Ti}(\mathrm{OH})_{4}, \mathrm{TiO}_{2}$ and $\mathrm{Fe}_{3} \mathrm{O}_{4}$, respectively. These results indicated that the Langmuir isotherm and Freundlich isotherm all fit the data but not very well. These may indicate adsorption of As(III) onto theses titanium and ferrous oxides due to complex actions of monolayer and multiple-layer coverage on homogeneous surface.

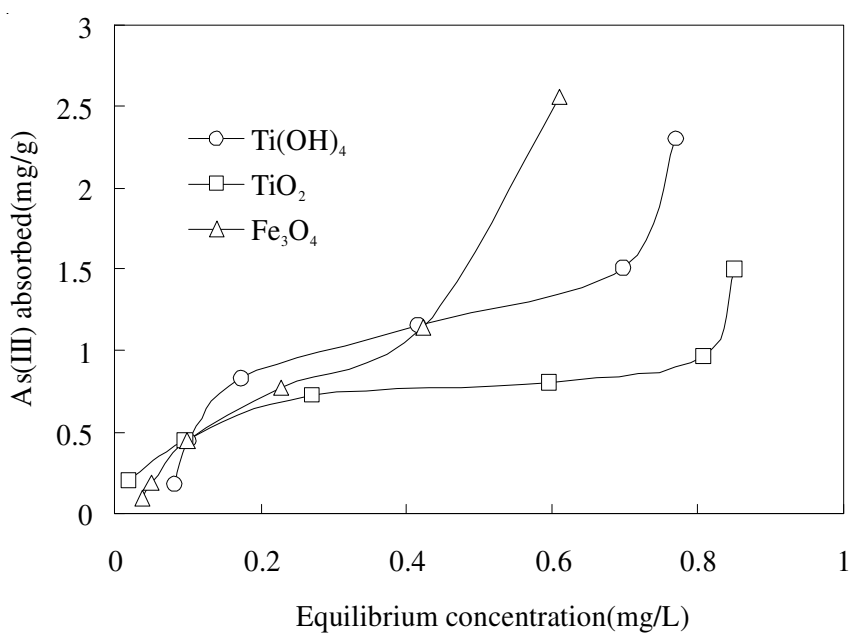

Fig. 6. Equilibrium adsorption of As(III) by vary adsorbents, with reaction conditions: initial As concentration $=1.00 \mathrm{mg} / \mathrm{L}$, contact time $=2 \mathrm{~h}$

\section{TABLE-1}

CORRELATION COEFFICIENT $\left(\mathrm{R}^{2}\right)$ OF LANGMUIR AND FREUNDLICH ISOTHERMS MODEL OF ARSENIC(III) ADSORPTION ON VARY ADSORBENTS

\begin{tabular}{lccc}
\hline Isotherm & $\mathrm{Ti}(\mathrm{OH})_{4}$ & $\mathrm{TiO}_{2}$ & $\mathrm{Fe}_{3} \mathrm{O}_{4}$ \\
\hline Langmuir & 0.932 & 0.984 & 0.928 \\
Freundlich & 0.934 & 0.943 & 0.963 \\
Dubinin-Radushkevich & 0.930 & 0.938 & 0.957 \\
\hline
\end{tabular}

Langmuir and Freundlich isotherms do not explain the adsorption mechanism. In order to get the idea about the type of adsorption the data were applied to Dubinin-Radushkevich (D-R) isotherm ${ }^{21,22}$, which can be expressed as eqn. 6 .

$$
\ln Q=\ln Q_{m}-k \varepsilon_{2}
$$

where, $\varepsilon$ (polanyi potential) can be expressed as:

$$
\varepsilon=R T \ln \left[\left(1+\left(1 / \mathrm{C}_{\mathrm{e}}\right)\right]\right.
$$

In the above equation, $\mathrm{Q}$ is the amount of arsenic adsorbed at equilibrium per unit weight of adsorbent $(\mathrm{mg} / \mathrm{g}), \mathrm{Q}_{\mathrm{m}}$ is the maximum adsorption capacity $(\mathrm{mg} / \mathrm{g}), \mathrm{C}_{\mathrm{e}}$ the equilibrium concentration of arsenic in the solution (ppm), $\mathrm{k}$ the constant related to adsorption energy $\left(\mathrm{mol}^{2} \mathrm{~kJ}^{-2}\right), \mathrm{R}$ is the gas constant $\left(\mathrm{kJ} \mathrm{mol}^{-1}\right.$ $\mathrm{K}^{-1}$ ) and $\mathrm{T}$ the temperature $(\mathrm{K})$. D-R isotherm was drawn by plotting $\ln Q$ against $\varepsilon^{2}$ (Fig. 9). $Q_{m}$ and $k$ were calculated from the slope and the intercept of the graph and found to be 19.22 $\mathrm{mg} / \mathrm{g}$ and $-0.049 \mathrm{~mol}^{2} \mathrm{~kJ}^{-2}$ of $\mathrm{Ti}(\mathrm{OH})_{4}, 4.64 \mathrm{mg} / \mathrm{g}$ and -0.0309 $\mathrm{mol}^{2} \mathrm{~kJ}^{-2}$ of $\mathrm{TiO}_{2}, 66.42 \mathrm{mg} / \mathrm{g}$ and $-0.0679 \mathrm{~mol}^{2} \mathrm{~kJ}^{-2}$ of $\mathrm{Fe}_{3} \mathrm{O}_{4}$, respectively, where $\mathrm{k}$ was independent of temperature.

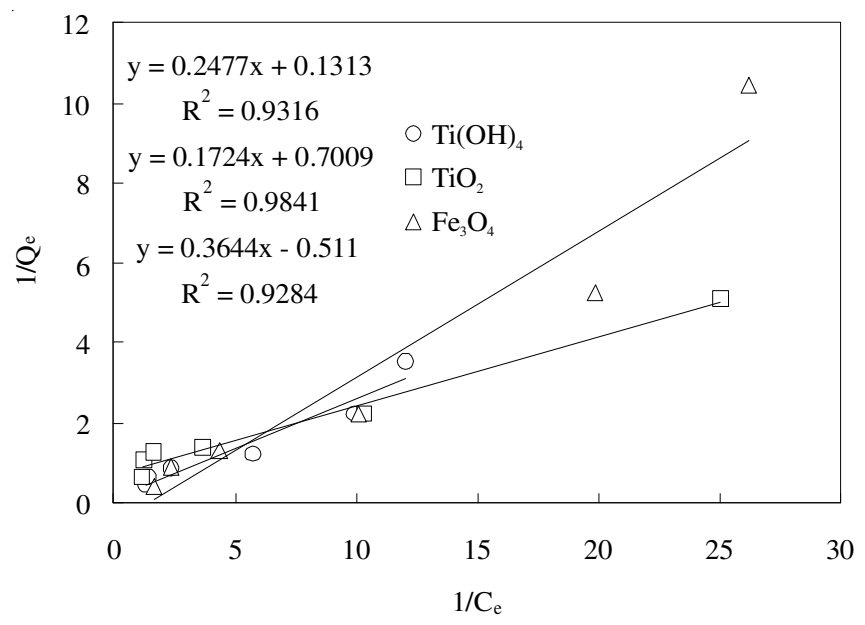

Fig. 7. Langmuir isotherm model for arsenic adsorption on titanium and ferrous oxide adsorbents

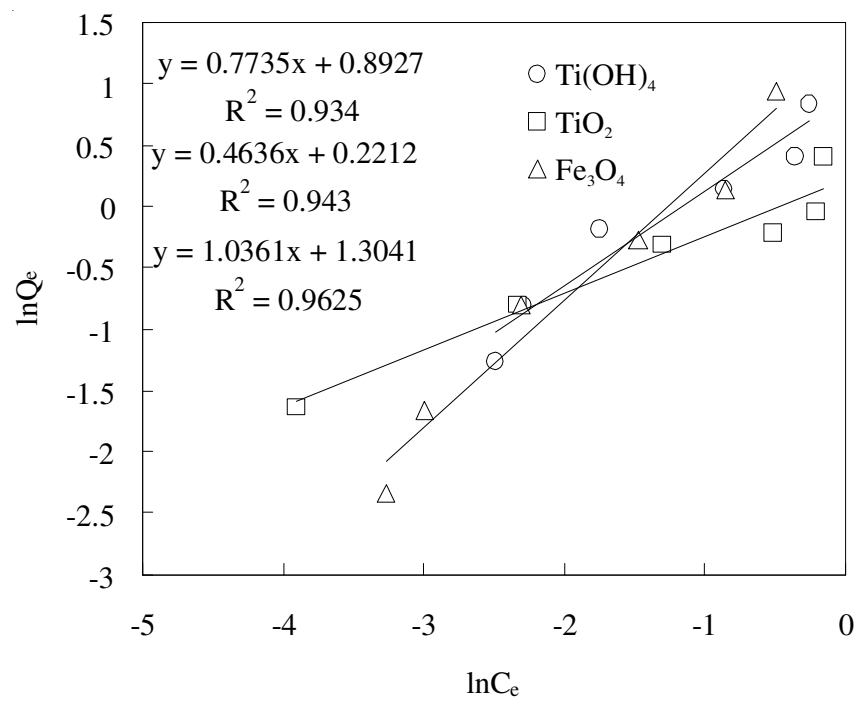

Fig. 8. Freundlich isotherm model for arsenic adsorption on titanium and ferrous oxide adsorbents

The mean free energy of adsorption (E), defined as free energy change when $1 \mathrm{~mol}$ of ion is transferred from solution to the surface of the adsorbent, was calculated from the $\mathrm{k}$-value using the following eqn. $7:^{15,20}$

$$
\mathrm{E}=(-2 \mathrm{~K})^{-0.5}
$$


If the value is more than $8 \mathrm{~kJ} \mathrm{~mol}^{-1}$, the adsorption type is considered as chemical reaction; and if it is $=8 \mathrm{~kJ} \mathrm{~mol}^{-1}$, then the adsorption is physical. The values of $\mathrm{E}$ found in this study were 3.19, 4.02 and $2.71 \mathrm{~kJ} \mathrm{~mol}^{-1}$ for $\mathrm{Ti}(\mathrm{OH})_{4}, \mathrm{TiO}_{2}$ and $\mathrm{Fe}_{3} \mathrm{O}_{4}$, respectively. This indicates that the adsorption is physical in nature. The adsorption of As(III) on titanium and ferrous oxide nano-particles were controlled by chemical process at initial stage but physical at latter as mentioned above. Most of the As(III) were chemical adsorbed on surface of adsorbent when equilibrium concentration is very low. If the equilibrium concentration of As(III) in solution exceed a critical point the adsorption should occurred in physical process. The calculated maximum adsorption capacity of As(III) on the adsorbents by $\mathrm{D}-\mathrm{R}$ isotherm shows the adsorption is physical in nature may indicate only very few chemical adsorbed As(III) molecular which can be neglect in the isotherm.

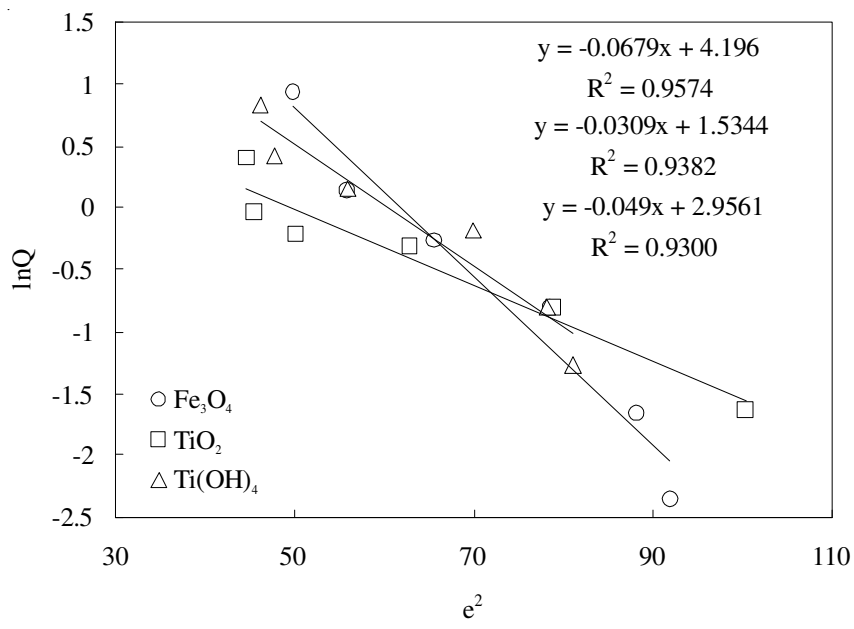

Fig. 9. Dubinin-Radushkevich isotherm model for arsenic adsorption on titanium and ferrous oxide adsorbents

\section{Conclusion}

Most of the As(III) in the solution can adsorb onto the adsorbents in a very short time, about $80 \%$ of As(III) be removed less than $40 \mathrm{~min}$. The adsorption was evaluated by the Langmuir, Freundlich and Dubinin-Radushkevich isotherm models. Maximum adsorption capacity ( $\mathrm{mg} / \mathrm{g}$ ) of the evaluated adsorbents caculated by $\mathrm{D}-\mathrm{R}$ isotherm were 19.22, 4.64 and $66.42 \mathrm{mg} / \mathrm{g}$ of the $\mathrm{Ti}(\mathrm{OH})_{4}, \mathrm{TiO}_{2}$ and $\mathrm{Fe}_{3} \mathrm{O}_{4}$, respectively. The adsorption mechanism follows the modified pseudo-secondorder reaction kinetics and the pores diffusion is the rate-limiting step. Results of adsorption isotherms and reaction kinetics suggested the adsorption of As(III) on titanium and ferrous oxide nano-particles were controlled by chemical process chemical process at low concentration but physical in high range.

\section{ACKNOWLEDGEMENTS}

This work was supported by the National Natural Science Foundation of China (NSFC, No. 50908001, 51078001), Key Special Program on the Science \& Technology for the Pollution Control and Treatment of Water Bodies (No. 2008ZX07316, 2008ZX07103), Special Science and Technology Foundation of Anhui Province (No. 08010301106), International Corporation Project of Science and Technology of Anhui Province (No. 09080703035) and the Anhui Natural Science and Technology Foundation (Excellent Youth Foundation No. 10040606Y29).

\section{REFERENCES}

1. L. Yan, H.H. Yin, S. Zhang, F.F. Leng, W.B. Nan and H.Y. Li, J. Hazard. Mater, 178, 209 (2010).

2. C. Christen, Environ. Sci. Technol., 38, 105A (2004).

3. D. Mohan and C.U. Pittman Jr., J. Hazard. Mater., 142, 1 (2007).

4. K. Wu, H. Wang, R. Liu, X. Zhao, H. Liu and J. Qu, J. Hazard. Mater, 185, 990 (2011).

5. Y. Li, F.-S. Zhang and F.-R. Xiu, Sci. Total Environ., 407, 5780 (2009).

6. H. Guo, D. Stüben and Z. Berner, J. Colloid Interf. Sci., 315, 47 (2007).

7. B. Manna and U.C. Ghosh, J. Hazard. Mater, 144, 522 (2007).

8. Z.C. Xu, Q. Li, S. Gao and J.K. Shang, Wat. Res., 44, 5713 (2010).

9. J.A. Lackovic, N.P. Nikolaidis and G.M. Dobbs, Environ. Eng. Sci., 17, 29 (2000).

10. M.S. Rahaman, A. Basu and M.R. Islam, Bioresour. Technol., 99, 2815 (2008).

11. M.E. Pena, G.P. Korfiatis, M. Patel, L. Lippincott and X. Meng, Water Res., 39, 2327 (2005).

12. N. Deedar, A. Irfan and Q. Ishtiaq, J. Environ. Sci., 21, 402 (2009).

13. P.K. Dutta, A.K. Ray, V.K. Sharma and F.J. Millero, J. Colloid Interf. Sci., 278, 270 (2004).

14. M. Pena, X.G. Meng, G. Korfiatis and C.Y. Jing, Environ. Sci. Technol., 40, 1257 (2006).

15. K. Gupta and U.C. Ghosh, J. Hazar. Mater, 161, 884 (2009).

16. M. Pirila, M. Martikainen, K. Ainassaari, T. Kuokkanen and R.L. Keiski, J. Colloid Interf. Sci., 353, 257 (2011).

17. K. Banerjee, G.L. Amy, M. Prevost, S. Nour, M. Jekel, P.M. Gallagher and C.D. Blumenschein, Water Res., 42, 3371 (2008).

18. Y.-N. Chen, L.-Y. Chai and Y.-D. Shu, J. Hazard. Mater, 160, 168 (2008).

19. M. Badruzzaman, P.K. Westerhoff and D. Knappe, Water Res., 38, 4002 (2004).

20. S.K. Maji, A. Pal and T. Pal, J. Hazard. Mater., 151, 811 (2008).

21. T.S. Singh and K.K. Pant, Sep. Purif. Technol., 36, 139 (2004).

22. S. Kundu and A.K. Gupta, Sep. Purif. Technol., 51, 165 (2006). 